\title{
Occurrence of phthalate acid esters (PAEs) in the northwestern Mediterranean Sea and the Rhone River
}

\author{
Paluselli Andrea ${ }^{1}$, Aminot Yann ${ }^{1}$, Galgani Francois ${ }^{2}$, Net Sopheak ${ }^{3}$, Sempéré Richard ${ }^{1,{ }^{*}}$
}

\begin{abstract}
${ }^{1}$ Aix-Marseille Univ., Université de Toulon, Mediterranean Institute of Oceanography (M I O), UM 110, CNRS, IRD, France

${ }^{2}$ IFREMER, Laboratoire Environnement Ressources, Provence Azur Corse (LER/PAC), Ifremer Centre de Méditerranée, ZP de Bregaillon, La Seyne sur Mer, France

${ }^{3}$ Université de Lille, Laboratoire de Spectrochimie Infrarouge et Raman (LASIR)-UMR CNRS 8516,

Villeneuve d'Ascq, France

* Corresponding author : Richard Sempéré, email address : richard.sempere@mio.osupytheas.fr
\end{abstract}

\begin{abstract}
:
Phthalate acid esters (PAEs) which are mainly anthropogenic molecules with endocrine disrupting effects in animals and humans, have been detected in terrestrial and aquatic environments. However, little is known about their distribution in the Mediterranean Sea, mainly because of analytical difficulties and the high possibility of ambient sample contamination. Here, we report the optimization of an existing protocol for the determination of PAEs in seawater and freshwater samples, as well as the first estimation of the source and distribution of phthalates acid esters (PAEs) in coastal waters from the NW Mediterranean Sea. By passing $1 \mathrm{~L}$ of sample through glass cartridges packed with $200 \mathrm{mg}$ of Oasis HLB and eluted with $6 \mathrm{~mL}$ of ethyl acetate, the recoveries for DMP, DEP, DPP, DiBP, DnBP, BzBP, DEHP and DnOP were 101, 98, 115, 110, 99, 98, 103 and 95\%, respectively, with acceptable blank values (below $0.4-4.0 \%$ of the masses measured in different seawater samples). By using this method, we detected PAEs in the Marseilles coastal area, offshore (2000 m depth) and in the Rhone River with total concentrations ranging from $75.3 \mathrm{ng} / \mathrm{L}$ offshore in surface water to $1207.1 \mathrm{ng} / \mathrm{L}$ a few meters above the bottom of the Marseilles Bay. High concentrations were also observed in deep waters offshore $(310.2 \mathrm{ng} / \mathrm{L})$ as well as in the Rhone River $(615.1 \mathrm{ng} / \mathrm{L})$. These results suggest that Marseilles urban area, Rhone River and sediment are potential sources of PAEs in the areas studied.

In the Rhone River, DEHP was the most abundant PAE (66.1\%) followed by DiBP (20.5\%) and DnBP $(6.6 \%)$, whereas a gradual change was observed in the plume of the river with increasing salinity. In the Marseilles Bay, DiBP was the most abundant PAE at the surface (47.3\% of total PAEs) followed by DEHP $(22.7 \%)$ and DnBP $(19.1 \%)$, whereas DnBP was predominant $(38.6 \%)$ a few meters above the bottom. By contrast, DEHP was the dominant species in the first $50 \mathrm{~m}(66.9-76.7 \%)$ offshore followed by DnBP (10.9-15.2\%), whereas DnBP was the most abundant $(57.0-72.6 \%)$ followed by DEHP (20.1$33.1 \%)$ in the deepest waters. This study suggests that in addition to direct PAEs injection in marine waters, different processes regulate PAE distribution in Mediterranean Sea including photochemical oxidation reactions, bacterial degradation and possible diffusion following release from marine litter near
\end{abstract}


the bottom.

\section{Highlights}

- First estimation of DMP, DEP, DiBP, DnBP, BzBP and DEHP concentration at Bay of Marseilles, northwestern Mediterranean Sea, Rhone River plume. First vertical profile $(0-1500 \mathrm{~m})$ of PAEs in offshore water. Variation of PAE composition from surface to the bottom water and from salinity value of 0 to 28. High DnBP concentration close to deep and bottom water probably for resuspension of PAE-rich sediments. Optimization of method for PAE detection at trace levels.

Keywords : Phthalates, DEHP, DMP, dissolved organic matter, endocrine disruptors 


\section{Introduction}

Phthalates or phthalic acid ester (PAEs) with low volatility and low water solubility are colorless and odorless. They are mainly produced by anthropogenic activity such as the manufacture and processing of plastic products (Simoneit et al., 2005; Serôdio and Nogueria, 2006; Lyche et al., 2009). Their annual production reached 8 million tons in 2011 (Net et al., 2015 and references therein) and they represent approximately $70 \%$ of the world consumption of plasticizer in 2014 (CEH, 2015). The structure of PAEs consists of a di-alkyl ester of $o$-benzenedicarboxylic acid. The most commercially significant PAEs, sorted by increasing number of carbons in the ester side chains, are dimethyl phthalate (DMP), diethyl phthalate (DEP), di-n-butyl phthalate (DnBP), benzylbutyl phthalate (BzBP), di-ethylhexyl phthalate (DEHP) and di-n-octyl phthalate (DnOP) the later being the most abundant (Holahan and Smith, 2015). PAEs of lower molecular weight are used as essential components of solvents, adhesives, waxes, pharmaceutical products, insecticide materials and cosmetics, whereas PAEs of higher molecular weight are instead used to improve the flexibility and handling of industrial materials (IARC, 2000; Halden, 2010). PAEs are mixed with the polymers and are not covalently bound to them. During aging, they are likely to migrate out of the plastic and to be released directly into the environment or inside an animal's stomach or tissue (Andrady, 2011).

As widely used compounds, PAEs are ubiquitous in terrestrial, marine and atmospheric environments (Xie et al., 2007; Fu et al., 2013; Dargnat et al., 2009; Gao et al., 2014; Staples et al., 1997; Net et al., 2014; 2015a-b; Wang et al., 2014). PAEs have been detected in surface seawater (Turner and Rawling, 2000; Horn et al., 2004; Brossa et al., 2005), in indoor air (Becker et al., 2004), in urban environments in soils (Ferreira and Morita, 2012), in urban lakes (Zeng et al., 2008), in drinking water (Yang et al., 2014), in terrestrial and marine remote aerosols (Xie et al., 2006, 2007; Fu et al., 2008, 2009, 2013), and in marine sediment, as well as in biota, including several aquatic species (Wofford et al., 1981), algae (Gao and Chi, 2015), and the tissues of mammals (Staples et al., 1997) and humans (Liou et al., 2014). PAEs can be degraded by some microalgal species (Gao and Chi, 2015), fish and shellfish (Munshi et al., 2013), bacteria (Chang et al., 2004) and intracellular and 
extracellular algal enzymes (Gao and Chi, 2015) as well as by the combined action of UV and $\mathrm{H}_{2} \mathrm{O}_{2}$ (Xu et al., 2007). PAEs are of particular concern to humans since they are considered as emerging environmental contaminants due to the endocrine disruption and carcinogenic effects detected in laboratory animal experiments and in humans (Crisp et al., 1998; Latini, 2005; Kamrin, 2009; Meeker et al., 2009).

The Mediterranean Sea is a semi-enclosed basin covering an area of 2.5 million $\mathrm{km}^{2}$ with a slow turnover time of $\sim 80$ years implying a sensitive response to anthropogenic impact (The Mermex group, 2011). Urbanization has been growing particularly along the coastline, with the result of a substantial modification of the coast and adverse effects on the quality of the environment (Pergent, 2012). There is a large range of industrial activities spread all along the Mediterranean basin, and a number of highly industrialized spots that are concentrated mainly in the northwestern Mediterranean Sea (Zorita et al., 2007). All these activities constitute a source of pollution through direct disposal, continental runoff and atmospheric transport (UNEP Chemicals, 2002; The Mermex group, 2011 and references therein). These industrial, agricultural and domestic activities generate a large volume of wastewater, which provides nutrients, trace metals (Cossa et al., 2017, this issue) organic matter, persistent organic pollutants (POPs) and related anthropogenic contaminants such as polycyclic aromatic hydrocarbons (PAHs) and polychlorinated dibenzo-p-dioxins and dibenzofurans (PCDD/Fs) (The Mermex group, 2011; Berrojalbiz et al., 2011; Guigue et al., 2011, 2014; Castro-Jiménez et al., $2008,2010,2012$ ) that impact the coastal marine ecosystems. The Mediterranean Sea is also impacted by marine litter and microplastics (Deudero and Alomar, 2015; Cózar et al., 2015; Faure et al., 2015; Pedrotti et al., 2016; Suaria et al., 2016 Schmidt et al., submitted), which can supply PAEs to surrounding waters during their degradation (Andrady, 2011). Although PAEs have already been detected in aquatic environments (Xie et al., 2005; Net et al., 2015), only a few studies have reported the occurrence of individual phthalates in the Mediterranean Sea (Sanchez-Avila et al., 2012; Brossa et al., 2005), and there is no study dealing with the distribution of a complete series of PAEs in the Mediterranean basin, including the sea and rivers, mainly because of analytical difficulties.

Indeed, PAE analysis of environmental samples is a challenging task because of the low 
concentrations, which is associated with the risk of contamination during sampling and processing in relation with their ubiquity in the laboratory atmosphere, tools, glassware and various containers (Net et al., 2015b and references therein). For environmental waters, several extraction procedures have already been used, including liquid-liquid (EPA, 1996; Zeng et al., 2008a; Li et al., 2013; Gao et al., 2014), solid-liquid (SLE), solid phase (SPE), magnetic (MSPE) dispersive (DSPE), solid phase micro extraction (SPME) (Zhang et al., 2013; Liou et al., 2014; Yang et al., 2014) and high volume sample techniques with PAD-2 resin columns and Soxhlet extractor (Xie et al., 2005). SPE appears to be an appropriate technique for seawater because of its ease of implementation, its ability to save time and solvent (compared to liquid-liquid extraction) and the decreased contamination (Zhang et al., 2013; Liou et al., 2014; Yang et al., 2014; Net et al., 2015b). However, the SPE protocol uses a tube made of polyethylene or polypropylene, which can release DiBP, DnBP and DEHP (Tienpont, 2004, Fasano et al., 2012, Bonini et al., 2008; Paluselli unpublished results). This technique has been used by a great number of reported protocols, concerning the type, amount and conditioning of the phase (Liou et al., 2014; Sanchez-Avila et al., 2011-2012; Yang et al., 2014) and the sample volume as well as the volume and type of solvent (He et al., 2013; Sanchez-Avila et al., 2011-2012; Yang et al., 2014; Liou et al., 2014). Previous protocols have shown a recovery variability ranging from 50-60\% to $120-150 \%$ (Del Carlo et al., 2008; Wang et al., 2008; He et al., 2013, Sanchez-Avila et al., 2011), especially for DEHP, which ranges from 60-80\% (He et al., 2013) to 151\% (Sanchez-Avila et al., 2011).

The objectives of this study are to examine, for the first time, the concentration levels and distribution of a homologous series of PAEs in the coastal northwestern Mediterranean Sea. This environmental study was associated with an optimization of a detection protocol for PAEs at trace level in seawater. Based on previous studies (Liou et al., 2014; Gao and Chi, 2015; Yang et al., 2014), conditions for the SPE extraction of PAEs have been modified and optimized for seawater. The method we report here was tested in seawater spiked with authentic standards and then applied to coastal and offshore Mediterranean seawater as well as to Rhone River freshwater in the framework of the 'Particule-MERMEX' project. 


\section{Experimental section}

\subsection{Materials and reagents}

The selected phthalates are dimethyl phthalate (DMP), diethyl phthalate (DEP), dipropyl phthalate (DPP), di-isobutyl phthalate (DiBP), di-n-butyl phthalate (DnBP), benzylbutyl phthalate (BzBP), di-ethylhexyl phthalate (DEHP) and di-n-octyl phthalate (DnOP). The deuterated internal standards were DEP-d4, DnBP-d4 and DEHP-d4. All native and labeled standards were of high purity grade (>98\%) and were purchased from Supelco (Bellefonte, USA). Stock solutions were prepared in hexane and stored in the dark at $4{ }^{\circ} \mathrm{C}$. Working solutions (unlabeled and labeled standards) were prepared by dilution of these solutions to $20 \mathrm{mg} / \mathrm{L}$. All solvents were glass-distilled grade and supplied by Rathburn Chemicals Ltd. (Walkerburn, UK). Ultra-pure water was produced on-site by a Milli-Q system, Millipore (Molsheim, France) with a specific resistivity of $18.2 \mathrm{M} \Omega . \mathrm{cm}\left(25^{\circ} \mathrm{C}\right)$ and a total organic carbon content of $<2 \mathrm{ppb}$. The extractions were carried out in controlled air conditions in an ISO class 6 cleanroom (temperature: $22^{\circ} \mathrm{C}$; SAS pressure: $+15 \mathrm{~Pa}$; SAS brewing rate: $30 \mathrm{vol} / \mathrm{h}$; lab pressure: $+30 \mathrm{~Pa}$; brewing rate: $50 \mathrm{vol} / \mathrm{h}$ ). All material was produced in borosilicate glass and that was previously kept in an acid bath overnight (10\% hydrochloric acid), rinsed with ultrapure water, combusted at $450{ }^{\circ} \mathrm{C}$ for 6 hours and rinsed with methanol and dichloromethane just before use.

\subsection{Solid phase extraction (SPE)}

The protocol was adapted from that of Yang et al. (2014) and Liou et al. (2014) and optimized for seawater in this study. The mentioned methods were modified in order to perform easy and rapid analysis on a large-scale with low contamination and to improve the recovery. The amount of Oasis HLB phase, the elution solvent type and volume, the sample volume, deuterated internal standards and glass materials were considered to improve the recoveries. Extraction cartridges were prepared in our laboratory with $200 \mathrm{mg}$ of Oasis HLB sorbent (Waters Corporation, $30 \mu \mathrm{m}, 100 \mathrm{~g}$ ) in a precombusted $6 \mathrm{~mL}$ glass reaction tube equipped with methanol-precleaned Teflon frits (Supelco, Sigma-Aldrich). SPE was conducted on a Visiprep vacuum manifold from Sigma-Aldrich (Saint Quentin Fallavier, France). Before sample extraction, the SPE cartridges were sequentially cleaned three times with $5 \mathrm{~mL}$ of acetone and $5 \mathrm{~mL}$ of dichloromethane. The cartridges were then conditioned with $5 \mathrm{~mL}$ of ethyl 
acetate, $5 \mathrm{~mL}$ of acetone and $5 \mathrm{~mL}$ of ultrapure water prior to sample processing. Seawater samples were spiked with DEP-d4, DnBP-d4 and DEHP-d4 at 50, 200 and $400 \mathrm{ng} / \mathrm{L}$, respectively, and percolated onto the cartridges under vacuum at a flow rate of 1-2 drops per second. After percolation, the cartridge was washed with $5 \mathrm{~mL}$ of ultrapure water to remove the remaining salt and dried under vacuum for $1 \mathrm{~h}$. The retained phthalates were then eluted with $2 \times 3 \mathrm{~mL}$ of ethyl acetate into precombusted $\left(450{ }^{\circ} \mathrm{C}, 6\right.$ hours) $10 \mathrm{~mL}$ vials. Ethyl acetate was then gently evaporated under a gentle stream of nitrogen (purity $>99,995 \%$ ) at room temperature to a final volume of $200 \mu \mathrm{L}$. The final samples were immediately closed with Teflon-lined screw caps, wrapped with Teflon ribbon and stored in the dark at $-20{ }^{\circ} \mathrm{C}$ until analysis.

\subsection{GC-MS analysis}

Analysis was performed using an Agilent Technologies 6850 GC system coupled to an Agilent Technologies 5975C mass spectrometer (GC/MS) operated with electron impact ionization $(70 \mathrm{eV})$. Chromatographic separation was achieved on an Agilent HP-5MS capillary column $(30 \mathrm{~m} \times 0.25 \mathrm{~mm}$, $0.25 \mu \mathrm{m}$ film thickness) with the $\mathrm{GC}$ oven programmed at $70{ }^{\circ} \mathrm{C}$ for 1 minute and then up to $230{ }^{\circ} \mathrm{C}$ at $30{ }^{\circ} \mathrm{C} / \mathrm{min}$, to $250{ }^{\circ} \mathrm{C}$ at $8{ }^{\circ} \mathrm{C} / \mathrm{min}$ and to $280{ }^{\circ} \mathrm{C}$ at $30{ }^{\circ} \mathrm{C} / \mathrm{min}$ with a final isothermal hold for 7.50 min. Helium was used as the carrier gas at a flow rate of $1.1 \mathrm{~mL} / \mathrm{min}$. The sample was manually injected $(2 \mu \mathrm{L})$ in splitless mode at an injector temperature of $250{ }^{\circ} \mathrm{C}$. A Merlin Microseal injector was used as a low carryover septum and a gas purifier (Charcoal, CP17972) was fitted on the carrier gas line to prevent contamination during injection. Data were acquired in selected ion monitoring (SIM) mode for increased sensitivity (SIM parameters given in Table 1) with a dwell time of $100 \mathrm{~ms}$. Two fragment ions were monitored per compound, with the most abundant ion used for quantification, except for DMP, DPP, DiBP and DnBP, which were ionized in a unique fragment. Data were collected and analyzed with the Agilent ChemStation software. The PAEs were quantified by isotopic dilution of 3 deuterated PAEs. The use of internal standard homologues to the target molecules has been shown to improve the recoveries by accurately compensating for loss of analyte during sample treatment (Aminot et al., 2015). The response factors were assessed for each analytical sequence from freshly prepared standards. 
Table 1. Retention time and ions for selected ion monitoring (SIM) of PAEs by GC/MS.

\begin{tabular}{ccccc}
\hline Compound & $\begin{array}{c}\text { Molar Mass } \\
\left(\mathbf{g ~ m o l}^{\mathbf{1}}\right)\end{array}$ & $\begin{array}{c}\text { Retention Time } \\
(\mathbf{m i n})\end{array}$ & $\begin{array}{c}\text { Quantifier ion } \\
\text { (abundance) }\end{array}$ & $\begin{array}{c}\text { Qualifier ion } \\
\text { (abundance) }\end{array}$ \\
\hline DMP & 194.2 & 5.55 & $163(100)$ & $194,135,77$ \\
DEP & 222.2 & 6.12 & $149(100)$ & 222,121 \\
DPP & 250.0 & 6.84 & $149(100)$ & 209,191 \\
DiBP & 278.4 & 7.22 & $149(100)$ & 223,205 \\
DnBP & 278.4 & 7.65 & $149(100)$ & 223,205 \\
BzBP & 312.4 & 9.72 & $149(100)$ & 206,238 \\
DEHP & 390.6 & 10.62 & $149(100)$ & 279,167 \\
DnOP & 390.6 & 11.76 & $149(100)$ & 279 \\
DEP-d4 & 226.2 & 6.11 & $153(100)$ & 181 \\
DnBP-d4 & 282.4 & 7.64 & $153(100)$ & 209 \\
DnBP-d4 & 282.4 & 7.64 & $153(100)$ & 209 \\
DEHP-d4 & 394.6 & 10.61 & $153(100)$ & 171,283 \\
\hline
\end{tabular}

\subsection{Application to seawater and freshwater samples}

Seawater samples were collected from SUNMEX station in the northwestern Mediterranean Sea, Bay of Marseilles $\left(43^{\circ} 18^{\prime}\right.$ N, $05^{\circ} 22^{\prime}$ E) in October 2014 and offshore at 'Antares station' (42 $47 ' 856$ N; $6^{\circ} 04395$ E) in March 2015 (Fig. 1), with a 12 L GO-Flo bottle previously rinsed with 1\% hydrochloric acid and ultrapure water to avoid contamination. The Go-Flo bottle tested with Milli-Q water showed only trace levels of PAEs which were not substracted from our dissolved PAEs concentrations in this study. Immediately after collection, seawater samples were transferred into $5 \mathrm{~L}$ precombusted glass bottles. Additional samples were directly collected in the Rhone River and Rhone River plume in March 2014 using 5 L precombusted glass bottles. General information on the Marseilles Bay, the Antares station and the Rhone River were given by Sempéré et al. (2015), Martini et al. (2016) and Sempéré et al. (2000), respectively. Less than two hours after collection, the samples were filtered through precombusted $\left(450{ }^{\circ} \mathrm{C}\right.$ for $6 \mathrm{~h}$ ) GFF filters $(47 \mathrm{~mm}$ filter diameter, rinsed with 2 $\mathrm{L}$ of Milli-Q water and $150 \mathrm{~mL}$ of sample prior to filtration) in a precombusted glass apparatus directly in a filtered-air clean laboratory. Milli-Q water rinse limit additional contamination (Yoro et al., 1999). 
After filtration, duplicate subsamples $(10 \mathrm{~mL})$ were poisoned with sulfuric acid to approximately $\mathrm{pH} 2$ to avoid any biological activity and stored in the dark in precombusted Teflon-capped glass vials for dissolved organic carbon (DOC) analysis. DOC concentrations were measured using a Shimadzu TOC-5000 carbon analyzer (Sempéré et al., 2008). Some seawater samples (Bay of Marseilles) were spiked with authentic PAEs (from 5 to $800 \mathrm{ng} / \mathrm{L}$ final concentration) to perform recovery experiments. All the seawater analyses were conducted in duplicate in the laboratory in Marseilles.

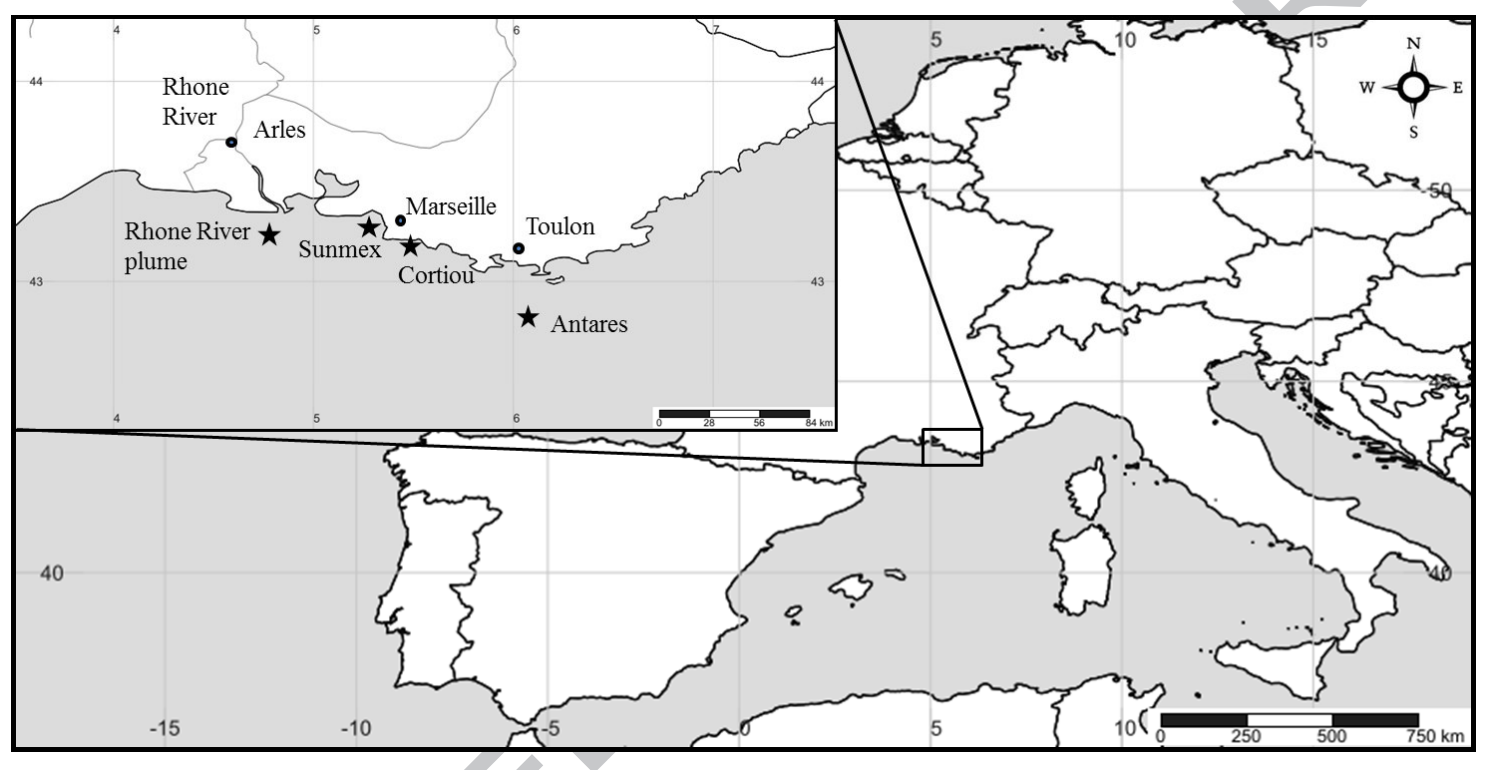

Figure 1. Area of study. The map shows the sampling stations: SUNMEX in the Bay of Marseilles (October 2014), offshore 'Antares station' (March 2015), Arles in Rhone River and the river plume (March 2014).

\section{Results and Discussion}

\subsection{Extraction of PAEs in seawater samples (optimization of the method)}

Numerous factors are known to significantly influence the efficiency of SPE extraction of phthalates from water. The most influential factors are elution the solvent, sample volume and sorbent mass. To increase the recovery, the elution solvent, sample volume and sorbent mass were studied in order to optimize efficient and reliable conditions for SPE extraction of seawater samples. 
Acetone

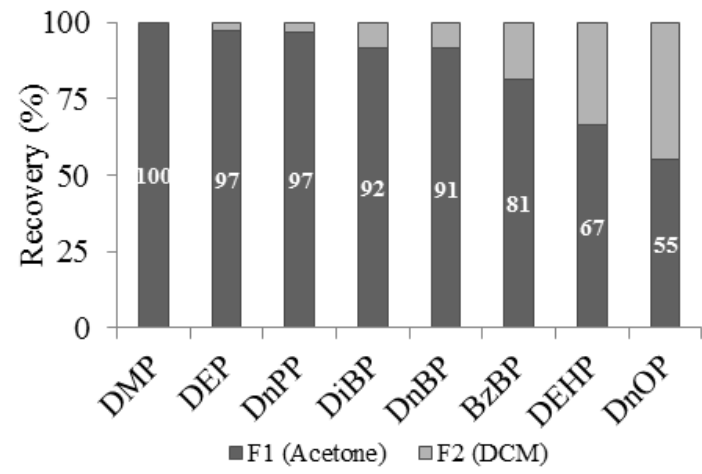

Ethyl Acetate

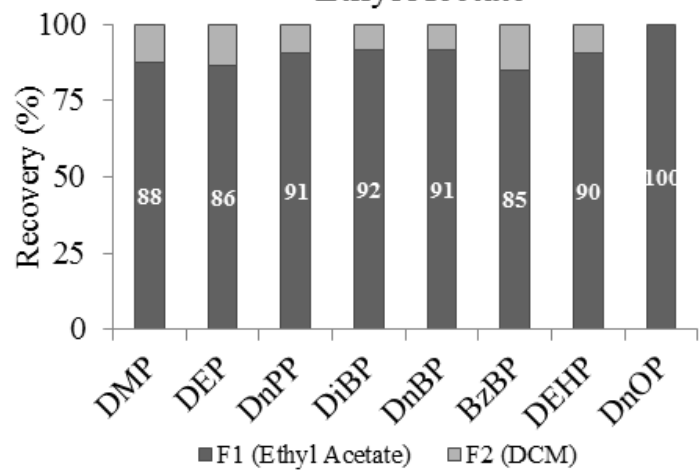

n-hexane

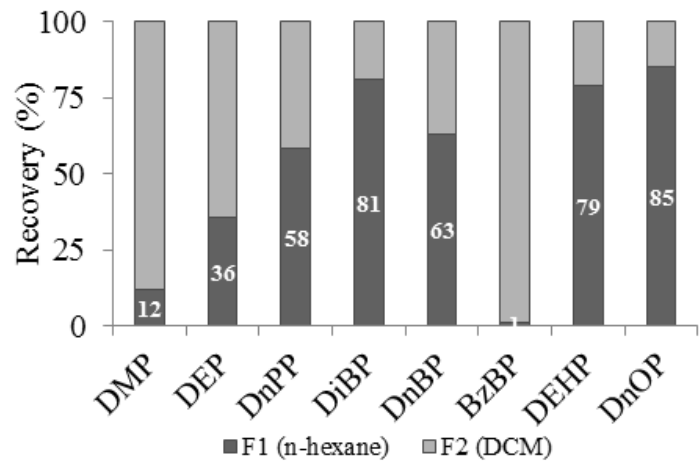

Methanol

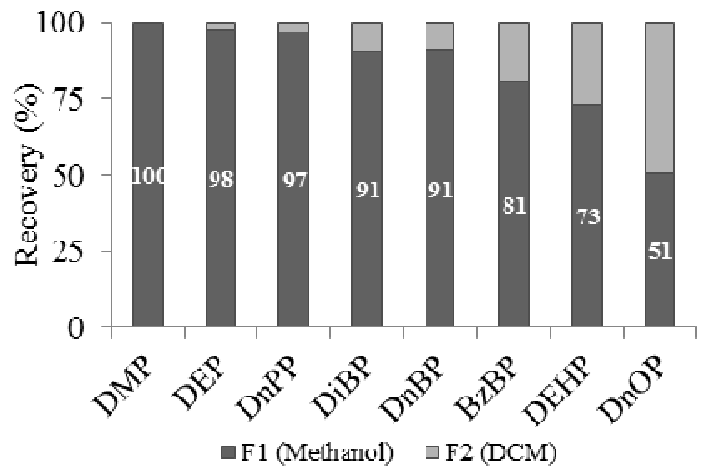

Dichloromethane

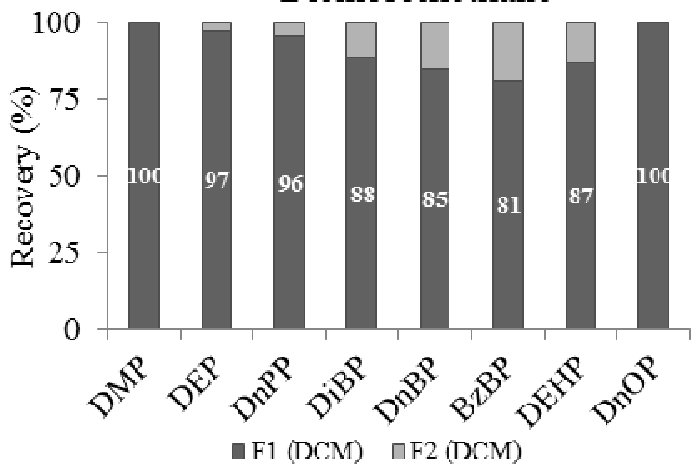

Figure 2. Recovery of PAEs obtained in two elution fractions carried out with five different organic solvents (F1) and dichloromethane (F2).

\section{a) Elution solvent effect}

First, $10 \mu \mathrm{L}$ of $20 \mathrm{mg} / \mathrm{L}$ PAE solution was passed through the cartridges, and two fractions of elution were collected. The first fraction was eluted with $5 \mathrm{~mL}$ of either acetone, dichloromethane, ethyl acetate, methanol or $\mathrm{n}$-hexane, and the second fraction was systematically eluted with $5 \mathrm{~mL}$ of dichloromethane in order to elute the remaining PAEs off the cartridge. Internal standards were spiked directly in the eluted fraction. The repartition of PAEs between the two fractions is given in Fig. 2. 
Acetone, dichloromethane, ethyl acetate and methanol yielded acceptable recoveries ranging from 55 to $100 \%$ while n-hexane was satisfactory only for DEHP and DnOP (79-85\%), with $12 \%$ for DMP, $36 \%$ for DEP and $1 \%$ for BzBP. n-Hexane is a better solvent for aliphatic compounds, unlike DMP, DEP (short carbon chain) and BzBP (higher aromaticity).

Acetone and methanol showed a similar elution strength with recoveries of $80-100 \%$ for DMP, DEP, DPP, DiBP, DnBP and BzBP in the first fraction and $70 \%$ and $50 \%$ for DEHP and DnOP, respectively. This result is consistent with the studies of Liou et al. (2014) and Yang et al. (2014), which performed the elution with $6 \mathrm{~mL}$ of methanol. Dichloromethane and ethyl acetate both indicated high recoveries for all PAEs in the first fraction and were the most appropriate elution solvents. Dichloromethane was the most appropriate elution solvent for DMP (100 \%), DEP (98 \%) and DPP (97\%), whereas ethyl acetate was the most appropriate for the elution of DiBP (91\%), DnBP (92\%), BzBP (85\%) and DEHP (90\%). DnOP was efficiently eluted (100\%) with both solvents. Previously, published protocols used $10 \mathrm{~mL}$ of dichloromethane/n-hexane (He et al., 2013) or $10 \mathrm{~mL}$ of acetone/dichloromethane (Sanchez-Avila et al., 2011; 2012) as the elution solvent. When comparing their recoveries and those from our developed protocol, the combination of dichloromethane with acetone seems to be more effective for PAE elution than its combination with nhexane. In these protocols, the ability to elute PAEs from the cartridges was improved by increasing the elution solvent volume to 10 and $20 \mathrm{~mL}$, respectively. According to our results, ethyl acetate is the best solvent for PAE elution.

\section{b) Seawater volume and sorbent mass effects}

As high SPE enrichment factors are required to compensate for the likely low PAE levels in seawater, it is important to ensure that the analytes do not breakthrough the sorbent at high percolation volumes. Increasing volumes $(100 \mathrm{~mL}, 200 \mathrm{~mL}, 500 \mathrm{~mL}$ and $1000 \mathrm{~mL})$ of seawater collected at Sunmex station at a $1.5 \mathrm{~m}$ depth were spiked with $10 \mu \mathrm{L}$ of $20 \mathrm{mg} / \mathrm{L}$ PAEs and percolated through either $200 \mathrm{mg}$ (Liou et al., 2014) or $400 \mathrm{mg}$ of sorbent. For each experimental condition, two additional samples were kept unspiked and were processed in the same conditions (blank samples). The recoveries were calculated as the difference between the concentration in the spiked and unspiked samples. In this experiment, the deuterated internal standards DEP-d4, DnBP-d4 and DEHP-d4 were 
spiked after the elution of the solvent. The recoveries of the extractions obtained with 4 different volumes of spiked seawater for 200 and $400 \mathrm{mg}$ of HLB sorbent are given in Table 2.

Table 2. Recoveries of PAE extractions obtained with 4 different volumes of spiked seawater and 200 and $400 \mathrm{mg}$ of HLB sorbent.

\begin{tabular}{|c|c|c|c|c|c|c|c|c|}
\hline \multirow{4}{*}{ Compounds } & \multicolumn{8}{|c|}{ Recoveries (\%) } \\
\hline & \multicolumn{4}{|c|}{$200 \mathrm{mg}$} & \multicolumn{4}{|c|}{$400 \mathrm{mg}$} \\
\hline & 100 & 200 & 500 & 1000 & 100 & 200 & 500 & 1000 \\
\hline & $\mathbf{m L}$ & $\mathbf{m L}$ & $\mathbf{m L}$ & $\mathbf{m L}$ & $\mathbf{m L}$ & $\mathbf{m L}$ & $\mathrm{IL}$ & $\mathbf{m L}$ \\
\hline DMP & 99 & 108 & 100 & 105 & 114 & 107 & 109 & 110 \\
\hline DEP & 61 & 93 & 88 & 89 & 95 & 93 & 95 & 100 \\
\hline DPP & 105 & 117 & 113 & 120 & 122 & 121 & 119 & 114 \\
\hline DiBP & 96 & 122 & 111 & 123 & 121 & 100 & 107 & 115 \\
\hline DnBP & 79 & 75 & 63 & 66 & 136 & 77 & 67 & 82 \\
\hline BzBP & 102 & 125 & 94 & 106 & 126 & 104 & 87 & 97 \\
\hline DEHP & 14 & 13 & 8 & 10 & 11 & 7 & 21 & 6 \\
\hline DnOP & 8 & 10 & 15 & 10 & 10 & 6 & 24 & 6 \\
\hline
\end{tabular}

The volume of the sample does not significantly affect the recovery of most of the PAEs, indicating the absence of breakthrough. Only DEP and DnBP were marginally affected by increasing sample volumes. The recovery of DEP increased from $60 \%$ with $100 \mathrm{~mL}$ to $93 \%$ with all other volumes on $200 \mathrm{mg}$ of sorbent. However, the recovery was stable between 93 and $100 \%$ on $400 \mathrm{mg}$. DnBP showed the opposite trend, where the recovery decreased from $75-79 \%$ with $100-200 \mathrm{~mL}$ to $63-$ $66 \%$ with 500-1000 mL on both $200 \mathrm{mg}$ and $400 \mathrm{mg}$ of sorbent. Acceptable recoveries (93-120\%) were determined for DMP, DPP, DiBP and BzBP under all experimental conditions. The two most hydrophobic PAEs DEHP and DnOP exhibited lower recoveries regardless of the experimental conditions, attributed to their potential for adsorption onto glassware. Such losses were corrected for by the use of deuterated DEHP as an internal standard (Table 3).

Above all, the volume of the sample did not significantly influence the performance of the HLB sorbent toward PAEs. Similar results were observed for the sorbent mass. The DnOP concentration in seawater is expected to be low, indicating the need to increase the enrichment factor 
by extracting $1 \mathrm{~L}$ of sample. BzBP is also characterized by low concentrations in seawater and by relatively high instrumental detection limits, confirming the need for a large volume of sample. As the differences between 200 and $400 \mathrm{mg}$ of sorbent did not justify the use of double the amount of sorbent, $200 \mathrm{mg}$ of sorbent was selected to reduce the price and time for a single extraction. Previously, published protocols reported the use of $1 \mathrm{~L}$ of matrix, but different amounts of solid phase, from 200 mg (Liou et al., 2014) to $500 \mathrm{mg}$ (Yang et al., 2014). According to the results, our optimized conditions were $200 \mathrm{mg}$ of HLB phase prepared in a combusted glass tube, $1 \mathrm{~L}$ of sample volume, and $6 \mathrm{~mL}$ of ethyl acetate as the elution solvent, split in two steps.

\subsection{Method validation}

Blank, response linearity and extraction validation

Procedural blank samples were examined by passing dry air and ethyl acetate directly through the precleaned cartridge and measuring the PAEs directly in the elution solution. Linearity was investigated over an eight-point calibration ranging from 50 to $6000 \mathrm{pg}$ injected. Instrumental repeatability was measured through the relative standard deviation of 10 injections of the same standard solution, corresponding to $100 \mathrm{pg}$ injected, whereas instrumental detection limits (IDLs) were extrapolated for a signal-to-noise ratio of 3 . The noise region was equivalent to the width of the peak before the peak, and the noise value was taken as the average height ("RMS" mode). The recoveries were calculated from the spiked seawater samples $(10 \mu \mathrm{L}$ of $20 \mathrm{mg} / \mathrm{L}$ of PAEs in $1 \mathrm{~L})$ after subtraction of the concentrations measured for the unspiked seawater samples $(n=2)$. Such experiments were repeated with half the spiked concentration ( $5 \mu \mathrm{L}$ of $20 \mathrm{mg} / \mathrm{L}$ of PAEs) in seawater samples $(\mathrm{n}=2)$ to study the influence of the concentration level.

The method was applied to $1 \mathrm{~L}$ seawater samples to minimize contamination and to allow the detection of low concentrations of BzBP and DnOP in seawater. The samples were passed through 200 mg of HLB sorbent, and the cartridges were eluted twice with $3 \mathrm{~mL}$ of ethyl acetate. A typical gas chromatogram of the PAEs isolated from the seawater samples collected in the Marseilles Bay is given in Figure 3. Identification of the PAEs was confirmed by GC/MS. Despite the precautions taken to prevent contamination, DEP, DiBP and occasionally DnBP were detected in the blanks at levels that 
remained below $0.4-2 \%, 2-3 \%$ and $0-4 \%$ of the masses measured in different seawater samples, respectively. The average recoveries of PAEs spiked in the seawater samples (Table 3) showed acceptable recoveries for all the phthalates, ranging from $97 \%$ of DEP to $110 \%$ of DiBP. The high recoveries obtained at low spiking levels also validated the appropriate performance of the protocol. To assess the influence of the concentration level on the recoveries, $1 \mathrm{~L}$ aliquots of seawater collected in the Bay of Marseilles were spiked at increasing concentration levels (standard addition technique). Different ranges of spiked concentrations were used depending on the initial concentration of the compound in seawater (from 5 to $40 \mathrm{ng} / \mathrm{L}$ for DMP, DEP, DPP, BzBP and DnOP and from 40 to 800 $\mathrm{ng} / \mathrm{L}$ for DiBP, DiBP and DEHP). Excellent correlation coefficients $\left(\mathrm{R}^{2}>0.96\right)$ and recoveries (between 95 and $116 \%$ ) indicate that the method is linear and accurate for all compounds, including DEHP $\left(\mathrm{R}^{2}=0.987 ; \mathrm{n}=7\right)$ and $\operatorname{DnOP}\left(\mathrm{R}^{2}=0.962 ; \mathrm{n}=5\right)$, in a range of environmentally realistic concentrations.

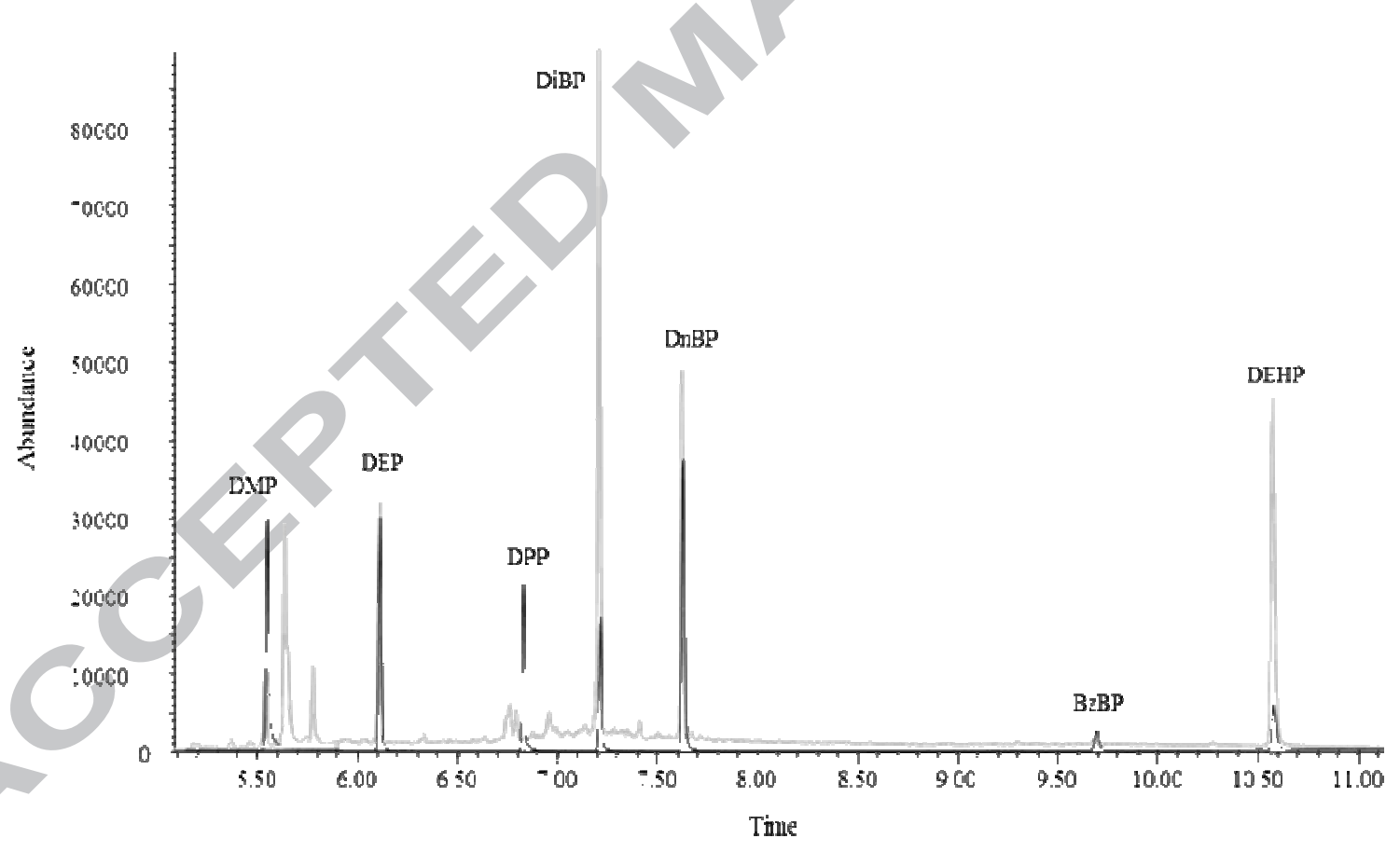

Figure 3. Typical capillary gas chromatogram of PAEs (DMP, DEP, DiBP, DnBP, BzBP and DEHP) isolated from the seawater sample (grey line) collected from the Marseilles Bay (northwestern Mediterranean Sea) in October 2014 and typical PAEs standard solution chromatogram (black line, 0.1 $\mathrm{mg} / \mathrm{L}$ ). The identification of PAEs was confirmed by GC/MS. The mass spectra of the PAEs (not presented here) were in accordance with those published in the literature. DPP and DnOP were not detected in this sample. 
Table 3. Statistical data of the linear regression between the spiked concentration of PAEs and the measured peak areas. PAE recovery was reported.

\begin{tabular}{lllccccc}
\hline Compound & $\begin{array}{l}\text { spiked concentration } \\
\left(\mathbf{n g ~ \mathbf { L } ^ { - 1 }}\right)\end{array}$ & $\mathbf{n}$ & $\mathbf{R}^{\mathbf{2}}$ & $\begin{array}{c}\text { slope } \\
\left(\boldsymbol{\mu} \mathbf{V s} / \mathbf{n g ~ \mathbf { L } ^ { - 1 }}\right)\end{array}$ & $\begin{array}{c}\mathbf{y} \text {-intercept } \\
(\boldsymbol{\mu} \mathbf{V s})\end{array}$ & $\begin{array}{c}\text { Recovery } \\
(\boldsymbol{\%})\end{array}$ & $\begin{array}{c}\text { MDL } \\
(\mathbf{n g} / \mathbf{L})\end{array}$ \\
\hline DMP & $0,5,10,20,40$ & 5 & 0.98 & 11022 & 20671 & 101.2 & 0.11 \\
DEP & $0,5,10,20,40,100$ & 6 & 0.99 & 13978 & 40049 & 98.1 & 0.21 \\
DPP & $0,5,10,20,40$ & 5 & 0.98 & 12072 & 2893 & 115.5 & 0.31 \\
DiBP & $0,40,100,200,400,600,800$ & 7 & 0.99 & 11006 & 5477511 & 110.4 & 0.23 \\
DnBP & $0,40,100,200,400,600$ & 6 & 0.99 & 19424 & 1965660 & 99.7 & 0.28 \\
BzBP & $0,5,10,20,40$ & 5 & 0.99 & 2718 & 1845 & 98.7 & 1.67 \\
DEHP & $0,40,100,200,400,600,800$ & 7 & 0.99 & 1638 & 23076 & 103.8 & 0.93 \\
DnOP & $0,5,10,20,40$ & 5 & 0.96 & 268 & 323 & 95.0 & 2.73 \\
\hline
\end{tabular}

\subsection{Concentration of PAEs in the northwestern Mediterranean Sea and Rhone River}

All PAEs, excepted DPP and DnOP, were detected in the Mediterranean seawater and Rhone River samples (Table 4). We found that offshore (Antares site), the concentration of total PAEs ranged from $75.3 \mathrm{ng} / \mathrm{L}$ at the surface to $310.2 \mathrm{ng} / \mathrm{L}$ in the deepest water, from $244.5 \mathrm{ng} / \mathrm{L}$ to $1207.1 \mathrm{ng} / \mathrm{L}$ a few meters above the bottom in the Marseilles Bay and from 182.2 to $212.6 \mathrm{ng} / \mathrm{L}$ in the Rhone River plume and close to the Marseilles Cortiou water treatment plant outlet. Although particulate PAEs were not measured in this study, previous study indicated that DnBP, BzBP and DEHP particulate concentration may represent the 2, 29 and $43 \%$, respectively, of the dissolved concentration in coastal seawater (North Sea, Xie et al., 2005). Very limited data are available for the occurrence and fate of dissolved PAEs in marine water, especially in the Mediterranean Sea. DEHP concentrations detected in the seawater samples in our study were in the range of 50.7-296.5 ng/L. These concentrations were in the same range reported by Sanchez-Avila et al. (2012) for Catalan coastal water (Spain, NW Mediterranean Sea) and by Turner and Rowling (2000) for the south coast of the UK, respectively, with range of 31-617 ng/L and 99-2200 ng/L. However, our results were 10 times lower than those reported by Brossa et al. (2005) for the Spanish coast. Lower concentrations have been only reported for North Sea with concentration ranges of $0.5-5.3 \mathrm{ng} / \mathrm{L}$ for DEHP and $0.02-4.0 \mathrm{ng} / \mathrm{L}$ for DMP and DEP (Xie et al., 2005). 
Table 4. PAEs concentrations detected in different Mediterranean Sea samples: Surface Rhone River and associated Plume (March, 2014), Bay of Marseilles (October, 2014) and surface 'Cortiou' station (November, 2014).

\begin{tabular}{|c|c|c|c|c|c|c|c|c|c|}
\hline \multirow{2}{*}{ Compounds } & \multirow{2}{*}{$\begin{array}{c}\begin{array}{c}\text { Rhone } \\
\text { River }\end{array} \\
\mathbf{S}=\mathbf{0}\end{array}$} & \multicolumn{3}{|c|}{ Rhone River Plume } & \multicolumn{4}{|c|}{ Bay of Marseilles } & \multirow[t]{2}{*}{ Cortiou } \\
\hline & & $\mathrm{S}=10$ & $S=18$ & $\mathrm{~S}=\mathbf{2 8}$ & $1.5 \mathrm{~m}$ & $5 \mathrm{~m}$ & $15 \mathrm{~m}$ & $30 \mathrm{~m}$ & \\
\hline$\overline{\mathrm{DMP}}$ & 5.7 & 5.7 & 4.8 & 2.7 & 1.8 & 1.7 & 1.4 & 6.4 & 7.3 \\
\hline DEP & 30.5 & 29.0 & 30.2 & 16.4 & 12.7 & 6.9 & 7.1 & 50.0 & 33.5 \\
\hline DPP & n.d. & n.d. & n.d. & n.d. & n.d. & n.d. & n.d. & $n d$ & n.d. \\
\hline DiBP & 125.9 & 48.6 & 67.0 & 136.4 & 215.7 & 56.5 & 77.0 & 383.4 & 81.7 \\
\hline DnBP & 40.5 & 21.8 & 21.7 & 22.8 & 87.0 & 63.4 & 138.9 & 466.0 & 28.8 \\
\hline BzBP & 5.4 & 2.7 & 2.6 & 2.5 & 3.5 & 3.2 & 4.0 & 4.8 & 5.1 \\
\hline DEHP & 406.8 & 101.2 & 55.9 & 39.2 & 103.5 & 112.8 & 102.9 & 296.5 & 56.2 \\
\hline DnOP & n.d. & n.d. & n.d. & n.d. & n.d. & & n.d. & n.d. & n.d. \\
\hline Total & 615.1 & 209.0 & 182.2 & 220.0 & 424.2 & 244.5 & 331.3 & 1207.1 & 212.6 \\
\hline
\end{tabular}

In Marseilles Bay, the samples were characterized by high concentrations of PAEs in the surface waters, a slight decrease with the depth, probably because of microbial degradation, and then an increase close to the bottom (Table 4). DiBP was the most abundant at the surface (47.3\% of total PAEs) followed by DEHP $(22.7 \%)$ and DnBP $(19.1 \%)$, whereas DnBP was predominant $(38.6 \%)$ followed by DiBP (31.8 \%) and DEHP (24.6\%) a few meters above the bottom. DMP, DEP and BzBP were detected as 0.5, 2.5 and $0.8 \%$ of total PAEs, respectively (Table 5; Figure 4). The high concentration at the bottom suggests the resuspension of PAE-rich sediments. As marine litter has already been reported to be abundant near the bottom (M I O unpublished observations) of the Marseilles Bay, it is likely that PAEs in the surficial sediment were released during plastic debris aging through physico-chemical and biotic processes (Bakir et al., 2014). This seems to be more evident for DnBP, whose relative fraction showed a stronger variation. Different PAEs are usually used by industry during plastic polymer production in order to increase flexibility, transparency, durability and longevity of the different materials produced (Net et al., 2015b, and reference therein). DEHP and DnBP are used as plasticizer for soft PVC, PVA and rubber as well as fixative in paint and especially DnBP is essentially used for its viscosity reducing properties and compatibility with nonPVC mixture (ECHA, 2013). It is likely that the PAEs detected above the bottom depend on the type 
of material that accumulates in the sediment after sinking. In addition, microplastics could come from larger plastic debris that degrades into smaller pieces and microbeads, a type of microplastic that are added as exfoliants to health and beauty products and easily pass though water filtration systems and end up in the sea, could transfer attached pollutants and additive chemicals (Browne et al., 2007) in the water column. At Cortiou station, near the Marseilles wastewater treatment plant, the surface water PAE concentration averaged at $212.6 \mathrm{ng} / \mathrm{L}$ ( $\mathrm{sd} \pm 3.4$ ) (Table 4), detected $5-6 \mathrm{~m}$ from the Cortiou water treatment plant outlet, which was quite low during the studied period. DiBP was the most abundant PAE (38.4 \%), followed by DEHP (26.4 \%), DEP (15.7\%) and DnBP (13.5\%), with DMP and BzBP representing minor fractions (3.5 and $2.5 \%$, respectively) (Table 5; Figure 4). The relative abundance was not very different from what we detected in Marseilles Bay, with the only exception of DEP.

Table 5. PAE relative abundances (\%) detected in different Mediterranean Sea samples: Surface Rhone River and associated Plume (March, 2014), Bay of Marseilles (October, 2014) and surface 'Cortiou' station (November, 2014).

\begin{tabular}{|c|c|c|c|c|c|c|c|c|c|}
\hline \multirow{2}{*}{ Compound } & \multirow{2}{*}{$\begin{array}{r}\begin{array}{r}\text { Rhone } \\
\text { River }\end{array} \\
\mathbf{S}=0\end{array}$} & \multicolumn{3}{|c|}{ Rhone River Plume } & \multicolumn{4}{|c|}{ Bay of Marseilles } & \multirow[t]{2}{*}{ Cortiou } \\
\hline & & $\mathrm{S}=10$ & $S=18$ & $S=28$ & $1.5 \mathrm{~m}$ & $5 \mathrm{~m}$ & $15 \mathrm{~m}$ & $30 \mathrm{~m}$ & \\
\hline$\overline{\mathrm{DMP}}$ & 0.9 & 2.7 & 2.6 & 1.2 & 0.4 & 0.7 & 0.4 & 0.5 & 3.4 \\
\hline DEP & 5.0 & 13.9 & 16.6 & 7.5 & 2.8 & 2.8 & 2.1 & 4.1 & 15.7 \\
\hline DPP & n.d. & & n.d. & n.d. & n.d. & n.d. & n.d. & n.d. & n.d. \\
\hline DiBP & 20.5 & 23.3 & 36.8 & 62.0 & 47.3 & 23.1 & 23.3 & 31.8 & 38.4 \\
\hline DnBP & 66 & 10.4 & 11.9 & 10.4 & 19.1 & 25.9 & 42.0 & 38.6 & 13.5 \\
\hline BzBP & & 1.3 & 1.4 & 1.1 & 0.8 & 1.3 & 1.2 & 0.4 & 2.4 \\
\hline DEHP & 66.1 & 48.4 & 30.7 & 17.8 & 22.7 & 46.0 & 31.1 & 24.6 & 26.4 \\
\hline DnOP & n.d. & n.d. & n.d. & n.d. & n.d. & n.d. & n.d. & n.d. & n.d. \\
\hline
\end{tabular}




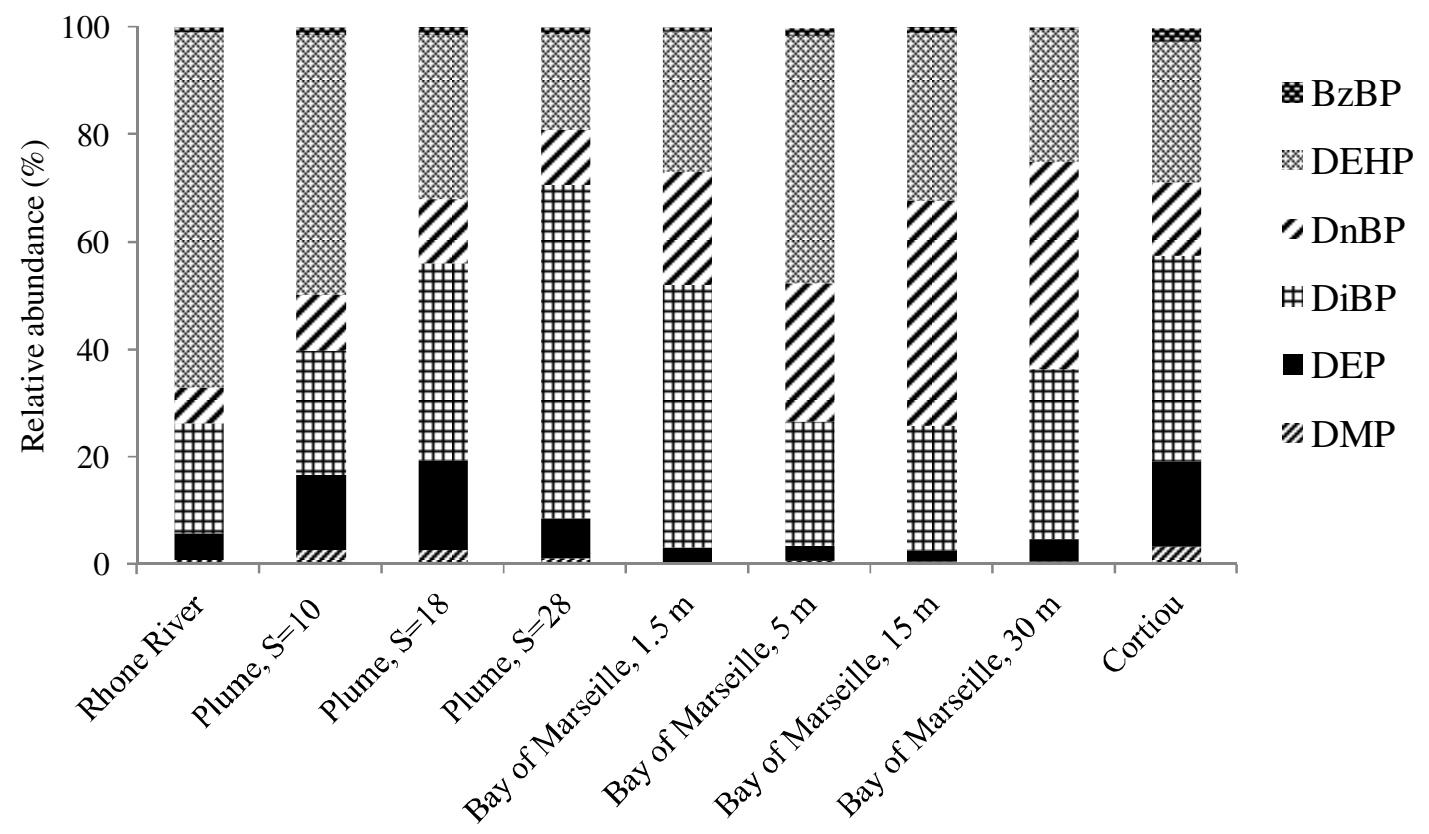

Figure 4. PAE relative abundances (\%) detected in different Mediterranean Sea samples: Surface Rhone River and associated Plume (March, 2014), Bay of Marseilles (October, 2014) and surface 'Cortiou' station (November, 2014).

Five PAEs were detected offshore in the 'Antares station' water column (Figure 5-6; Table 6). DnBP was characterized by a large range of concentrations $(8.2-225.5 \mathrm{ng} / \mathrm{L})$, which reached a maximum in deep water (Figure 6). With the exception of DnBP, the vertical profiles seem to have similar trends. The surface samples were characterized by high concentrations that slightly decrease down to 200-500 m. Then, the concentration started to increase down to $1500 \mathrm{~m}$, where the concentration was similar to that detected in the surface samples. The DnBP vertical profile was characterized by the same trend in the first meter of the water column, decreasing from 13.4 to 8.2 $\mathrm{ng} / \mathrm{L}$, but it was followed by a strongly increasing concentration in the deepest samples (87.3-225.5 ng/L). DEHP was the dominant species in the first $50 \mathrm{~m}$ (66.9-76.7 \% of total PAEs) followed by DnBP (10.9-15.2\%). Between 100 and 250 m, the relative abundance of DEHP was slightly lower (56.9-65.4\%), whereas that of DnBP was higher (25.8-28.5\%) up to the maximum salinity and minimum temperature. Under $500 \mathrm{~m}$, DnBP was the most abundant PAE (57.0-72.6 \%) followed by DEHP (20.1-33.1\%). DiBP, DMP and DEP were detected as minor fractions of the total PAEs detected in offshore waters, representing 7.9, 5.7 and $4.4 \%$ of total PAEs at the surface and 3.5, 2.3 and $1.5 \%$ in deepest waters, respectively (Fig. 5; Tab. 6). Note that this offshore station area is 
influenced by the shallow depth Northern Current (NC) with high seasonal variability (Millot, 1991), which may penetrate into the shelf of the Gulf of Lions (Barrier et al., 2016 and references therein).

Table 6. PAE relative abundances $(\%)$ detected in offshore Antares station-samples collected at the surface and at depths of 5, 50, 100, 250, 500,1000 and $1500 \mathrm{~m}$ in March 2015.

\begin{tabular}{lcccccccc}
\hline \multirow{2}{*}{ Compounds } & \multicolumn{8}{c}{ Depth (m) } \\
\cline { 2 - 9 } & $\mathbf{0}$ & $\mathbf{5}$ & $\mathbf{5 0}$ & $\mathbf{1 0 0}$ & $\mathbf{2 5 0}$ & $\mathbf{5 0 0}$ & $\mathbf{1 0 0 0}$ & $\mathbf{1 5 0 0}$ \\
\hline DMP & 5.7 & 5.1 & 5.0 & 3.5 & 7.9 & 4.6 & 3.5 & 2.3 \\
DEP & 4.4 & 2.3 & 2.0 & 1.9 & 2.3 & 1.6 & 1.7 & 1.5 \\
DiBP & 7.9 & 5.1 & 4.5 & 3.5 & 4.4 & 3.6 & 4.5 & 3.5 \\
DnBP & 15.2 & 10.9 & 15.2 & 25.8 & 28.5 & 57.0 & 61.0 & 72.6 \\
DEHP & 66.9 & 76.7 & 73.3 & 65.4 & 56.9 & 33.1 & 29.2 & 20.1 \\
\hline
\end{tabular}

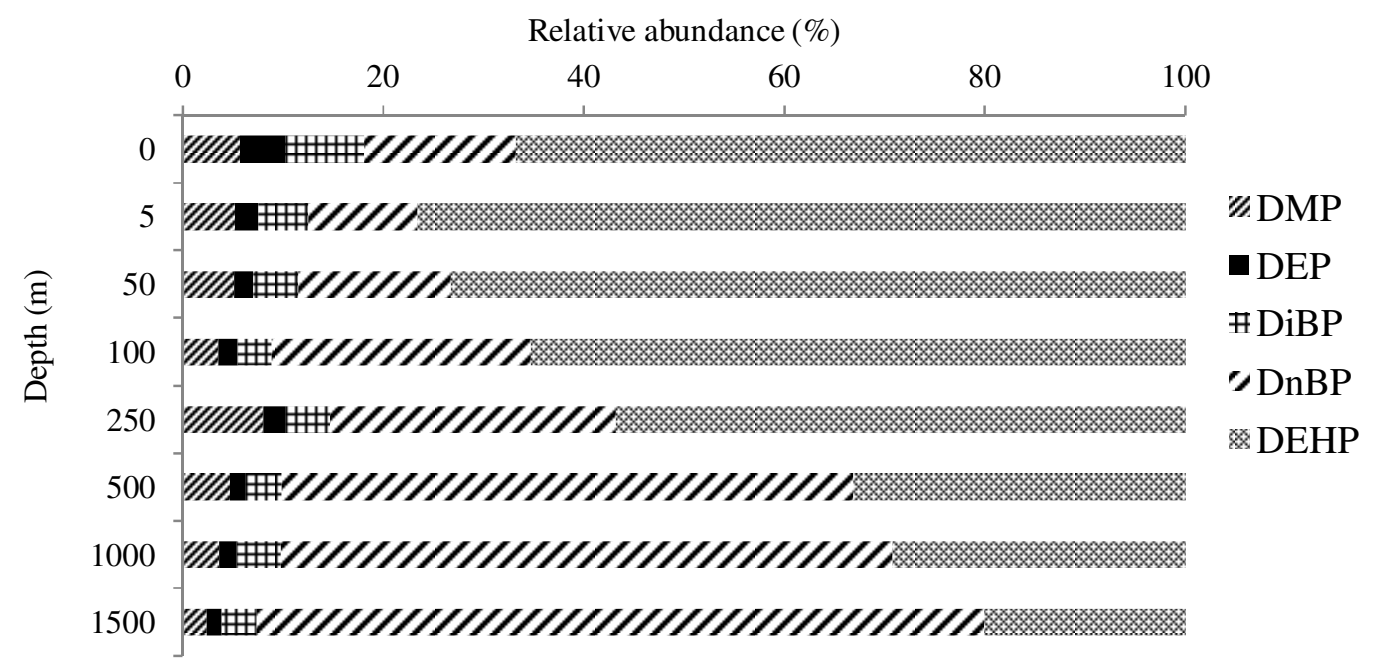

Figure 5. PAE relative abundances (\%) detected in offshore Antares station-samples collected at the surface and at depths of 5, 50, 100, 250, 500,1000 and $1500 \mathrm{~m}$ in March 2015.

This water originating eastward from the Italian coasts may carry plastic debris (Schmidt et al., submitted) and dissolved PAEs. The decrease in concentration in the first meter of the water column could be explained by biodegradation processes. The increase in concentration at 200-500 m suggests the production of PAEs from the aging of plastic debris, as was observed in Marseilles Bay. Indeed, the behavior of DnBP in the deepest water seems to reflect the same production observed close 
to the bottom of the Marseilles area. These data were the first attempt to investigate the vertical distribution of PAEs in the water column.
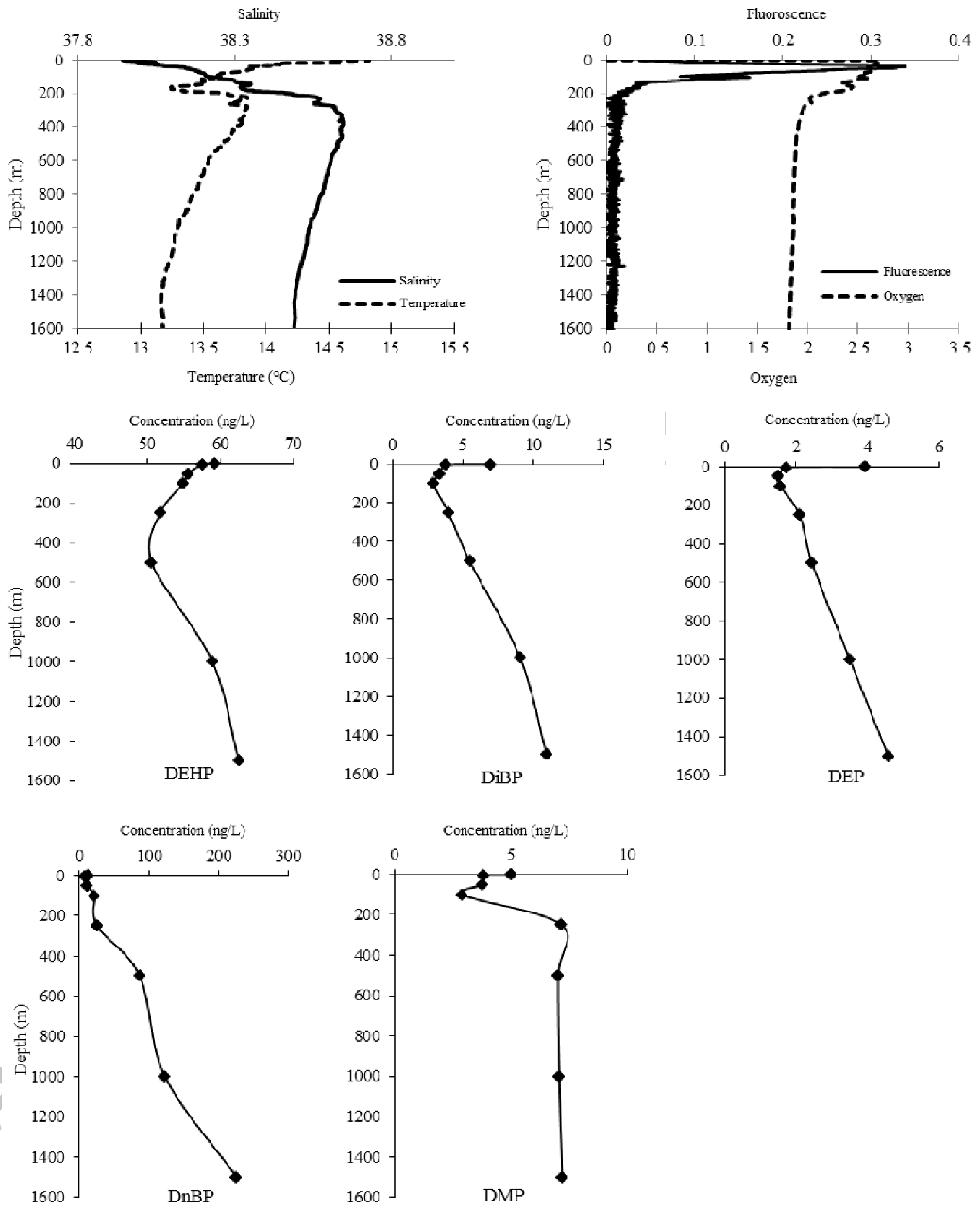

Figure 6. Vertical profile (0-1500 m) of 5 PAEs, along with salinity, temperature (a), fluorescence and oxygen (b) detected at offshore Antares station in March 2015. The compounds detected were: (c) diethylhexyl phthalate (DEHP), (d) di-iso-butyl phthalate (DnBP), (e) diethyl phthalate (DEP), (f) di-nbutyl phthalate (DnBP) and (g) dimethyl phthalate (DMP). 


\section{Rhone River and river mouth}

The total PAE concentrations ranged from $615.1 \mathrm{ng} / \mathrm{L}$ to $182.2-220.0 \mathrm{ng} / \mathrm{L}$ in the Rhone River plume (Table 4) suggesting that the Rhone is clearly a source of PAEs in the coastal area. Previous studies dealing with individual PAEs reported DMP concentrations in the range of $2.5-5.5 \mathrm{ng} / \mathrm{L}$ (SanchezAvila et al., 2012) in six rivers in Spain (Muga, Fluvià, Ter, Besòs, Llobregat and Ebro River). DEP was detected in different studies in the Seine River (France) in a range slightly higher than our data, from 46-208 ng/L (Teil et al., 2007) to 71-181 ng/L (Dargnat et al., 2009), as well as 52-284 ng/L in Spain (Sanchez-Avila et al., 2012). BzBP was also reported at low concentration in the range of 5-23 ng/L (Dargnat et al., 2009; Sanchez-Avila et al., 2012). Dargnat et al. (2009) and Teil et al. (2007) found similar concentrations of DEHP, 161-314 ng/L and 323-779 ng/L, respectively, in the Seine

River. We found that DEHP was the most abundant PAE (66.1\%) in the Rhone River followed by $\operatorname{DiBP}(20.5 \%)$ and DnBP (6.6 \%), whereas DMP, DEP and BzBP represented the smallest fractions (Table 5; Figure 4). The relative abundance of DEHP decreased from $66.1 \%$ of the total PAEs in the river $(\mathrm{S}=0)$ to $48.4,30.7$ and $17.8 \%$ in the plume stations $(\mathrm{S}=10-28)$. The opposite trend was observed for all other PAEs, especially for DnBP and DiBP, with DnBP values increasing from 6.6 to $11.9 \%$ and from 20.5 to $62.0 \%$ for DiBP. A similar trend was also observed for DMP and DEP. Changes in the relative abundance from the river to the plume could be due to different selective bacterial degradation and/or photodegradation processes occurring in the salty water. Only DiBP showed, after the concentration first decreased probably due to dilution effect, an increase in concentration and in relative abundance. This could be caused by some atmospheric input of this compound as it was already supposed in the Bay of Marseilles.

\section{Conclusion}

A reliable analytical technique for measuring PAEs in natural seawater samples at trace levels was slightly improved and allowed determination of PAEs in seawater. This technique consists of the adsorption on PAEs from acidified seawater samples onto $200 \mathrm{mg}$ Oasis HLB glass cartridges 
followed by elution with ethyl acetate and determination by GC/MS. The recoveries of the PAEs from spiked seawater samples were found to be between 95-115\%, and the contamination was strongly reduced by using a number of precautions. Our results showed that the Rhone River was a source of PAE in estuary and in coastal area. Although DEHP was predominant in the river, its relative abundance decreased with increasing salinities, DiBP being predominant in the plume for a salinity of 28. We reported, for the first time, the PAE vertical profile $(0-1500 \mathrm{~m})$ from the offshore water, which had lower concentrations compared to the Bay of Marseilles. We observed that DEHP was also predominant in surface marine waters including offshore $(0-250 \mathrm{~m})$ and below the surface in Marseille Bay $(5 \mathrm{~m})$. The opposite trend was found for DnBP for which concentrations significantly increased in mesopelagic waters. High concentrations of DnBP, DEHP and DiBP were detected close to the bottom (30 m) of the Bay of Marseilles. Such feature might be related to diffusion of PAEs released from the sediment surface very likely induced from plastic debris degradation and previously accumulated in the bottom. Precise origin of such material still needs to be determined. Other processes such as photochemical oxidation reactions in surface waters, bacterial degradation, are certainly important processes that regulate as well the distribution of PAEs in the water column. High PAE concentrations found in coastal area near Marseilles city strongly suggest that these organic compounds are very likely abundant in the whole Mediterranean that is surrounded by urbanized areas and that is submitted to relatively high inputs of rivers and atmospheric deposition compared to the global Ocean.

\section{Acknowledgments}

This study was conducted as part of the PARTICULE-Région PACA, MERMEXMISTRALS, AT-CONTAM of M I O, LABEX OT-Med projects supported by Pole Mer Méditerranée. This study is a contribution to the international SOLAS and LOICZ projects. We acknowledge the financial support from the PACA region, which provided a $\mathrm{PhD}$ scholarship for A. Paluselli. The authors are grateful to the crews of the R/V Antedon II and SAM-M I O platform for their operation at sea. 


\section{References}

Aminot, Y., Litrico, X., Chambolle, M., Arnaud, C., Pardon, P., Budzindki, H., 2015. Development and application of a multi-residue method for the determination of 53 pharmaceuticals in water, sediment, and suspended solids using liquid chromatography-tandem mass spectrometry. Analytical and Bioanalytical Chemistry 407 (28), 8589-8604.

Andrady, A.L., 2011. Microplastics in the marine environment. Marine Pollution Bulletin 62 (8), 1596-1605.

Bakir, A., Rowland, S.J., Thompson, R.C., 2014. Enhanced desorption of persistent organic pollutants from microplastics under simulated physiological conditions. Environmental Pollution 185, 16-23.

Barrier, N., Petrenko, A.A, Ourmières, Y., 2016. Strong intrusions of the Northen Mediterranean Current on the eastern Gulf of Lion: insights from in-situ observations and high resolution numerical modeling. Ocean Dynamics 66 (3), 313-327.

Becker, K., Seiwert, M., Angerer, J., Heger, W., Koch, H.M., Nagorka, R., Roßkamp, E., Schluter, C., Seifert, B., Ullrich, D., 2004. DEHP metabolites in urine of children and DEHP in house dust. International Journal of Hygiene and Environmental Health 207, 409-417.

Berrojalbiz, N., Dachs, J., Ojeda, M.J., Valle, M.C., Castro-Jimenez, J., Wollgast, J., Ghiani, M., Hanke, G., Zaldivar, J.M., 2011. Biogeochemical and physical controls on concentrations of polycyclic aromatic hydrocarbons in water and plankton of the Mediterranean and Black Sea. Global Biogeochemical Cycle 25 (4).

Bonini, M., Errani, E., Zerbinati, G., Ferri, E., Girotti, S., 2008. Extraction and gas chromatographic evaluation of plasticizers content in food packing film. Microchemical Journal 90, 31-36.

Brossa, L., Marcé, R., Borrull, F., Pocurull, E., 2005. Occurrence of twenty-six endocrine-disrupting compounds in environmental water samples from Catalogna, Spain. Environmental Toxicology and Chemistry 24, 261-267.

Browne M.A., Galloway T., Thompson R., 2007. Microplastic-an emerging contaminant of potential concern?. Integrated Environmental Assessment and Management 3 (4), 559-566.

Castro-Jimenez, J., Deviller, G., Ghiani, M., Loos, R., Mariani, G., Skejo, H., Umlauf, G., Wollgast, J., Laugier, T., Heas-Moisan, K., Leaute, F., Munschy, C., Tixier, C., Tronczynski, J., 2008. PCDD/F 
and PCB multi-media ambient concentrations, congener patterns and occurrence in a Mediterranean coastal lagoon (Etang de Thau, France). Environmental Pollution 156 (1), 123-125.

Castro-Jimenez, J., Eisenreich, S.J., Ghiani, M., Mariani, G., Skejo, H., Umlauf, G., Wollgast, J., Zaldivar, J.M., Berrojalbiz, N., Reuter, H.I., Dachs, J., 2010. Atmospheric occurrence and deposition of polychlorinated dibenzo-p-dioxins and dibenofurans (PCDD/Fs) in the open Mediterranean Sea. Environmental Science of Technology 44 (14), 5456-5463.

Castro-Jimenez, J., Berrojalbiz, N., Wollgast, J., Dachs, J., 2012. Polycyclic aromatic hydrocarbons (PAHs) in the Mediterranean Sea: Atmospheric occurrence, deposition and decoupling with settling fluxes in the water column. Environmental Pollution 166, 40-47.

CEH, 2015. Acrylic Resins and Plastics. Chemical Economic Handbook.

Chang, B.V., Yang, C.M., Cheng, C.H., Yuan, S.Y., 2004. Biodegradation of phthalates ester by two bacteria strains. Chemosphere 55 (4), 533-538.

Cossa, D., Fanget, A.S., Chiffoleau, J.F., Bassetti, M.A., Buscail, R., Dennielou, B., Briggs, K., Arnaud, M., Guédron, S., Berné, S., 2017. Chronology of anthropogenic trace elements accumulation in the Rhone pro-delta sediments (northwestern Mediterranean) during the last 400 years. MERMEX special issue Progress Oceanography, this issue.

Cozar, A., Sanz-Martin, M., Marti, E., Gonzalez-Gordillo, J.I., Ubeda, B., Galvez, J.A., Irigoien, X., Duarte, C.M., 2015. Plastic accumulation in the Mediterranean Sea. PLoS ONE 10 (4).

Crisp, T.M., Clegg, E.D., Cooper, R.L., Wood, W.P., Anderson, D.G., Baetcke, K.P., Hoffmann, J.L., Morrow, M.S., Rodier, D.J., Schaeffer, J.E., Touart, L.W., Zeeman, M.G., Patel, Y.M., 1998. Environmental endocrine disruption: an effects assessment and analysis. Environmental Health Perspectives 106 (1), 11-56.

Dargnat, C., Teil, M.J., Chevreuil, M., Blanchard, M., 2009. Phthalate removal throughout wastewater treatment plant: Case study of Marne Aval station (France). Science of The Total Environment 12351244.

Del Carlo, M., Pepe, A., Sacchetti, G., Compagnone, D., Mastrocola, D., Cichelli, A., 2008. Determination of phthalate esters in wine using solid-phase extraction and gas chromatography-mass spectrometry. Food Chemistry 111, 771-777. 
Deudero, S., Alomar, C., 2015. Mediterranean marine biodiversity under threat: Reviewing influence of marine litter on species. Marine Pollution Bulletin 98 (1-2), 58-68.

ECHA (European Chemicals Agency), 2013. Annex XV dossier proposal for identification of a substance as a CMR Cat 1 or 2.

EPA (Environmental Protection Agency), 1996. Phthalates esters by gas chromatography with electron capture detection (GC/ECD). Method 506.

Fasano, E., Bono-Blay, F., Cirillo, T., Montuori, P., Lacorte, S., 2012. Migration of phthalates, alkylphenols, bisphenol A and di(2-ethylhexyl)adipate from food packaging. Food Control 27 (1), 132-138.

Faure, F., Demars, C., Wieser, O., Kunz, M., De Alencastro, L.F., 2015. Plastic pollution in Swiss surface waters: nature and concentrations, interaction with pollutants. Environmental Chemistry 12 (5), 582-591.

Ferreira, I.D., Morita, D.M., 2012. Ex-situ bioremediation of Brazilian soil contaminated with plasticizers process wastes. Brazilian Journal of Chemical Engineering 29 (1), 77-86.

Fu, P., Kawamura, K., Okuzawa, K., Aggarwal, S.G., Wang, G., Kanaya, Y., Wang, Z., 2008. Organic molecular compositions and temporal variations of summertime mountain aerosols over Mt. Tai, North China Plain. Journal of Geophysical Research 11.

Fu, P., Kawamura, K., Barrie, L.A., 2009. Photochemical and other source of organic compounds in the Canadian high Artic aerosol pollution during winter-spring. Environmental Science and Technology 43, 286-292.

Fu, P., Kawamura, K., Chen, J., Charrière, B., Sempéré, R., 2013. Organic molecular composition of marine aerosols over the Arctic Ocean in summer: contributions of primary emission and secondary aerosol formation. Biogeosciences 10, 653-667.

Gao, D., Li, Z., Wen, Z., Ren, N., 2014. Occurrence and fate of phthalate esters in full-scale domestic wastewater treatment plants and their impact on receiving waters along the Songhua River in China. Chemosphere 95, 24-32. 
Gao, J., Chi, J., 2015. Biodegradation of phthalate acid esters by different marine microalgal species. Marine Pollution Bulletin 99, 70-75.

Guigue, C., Tedetti, M., Giorgi, S., Goutx, M., 2011. Occurrence and distribution of hydrocarbons in the surface microlayer and subsurface water from the urban coastal marine area off Marseilles, Northwestern Mediterranean Sea. Marine Pollution Bulletin 62 (12), 2741-2752.

Guigue, C., Tedetti, M., Ferretto, N., Garcia, N., Goutx, M., 2014. Spatial and seasonal variabilities of dissolved hydrocarbons in surface waters from the Northwestern Mediterranean Sea: Results from one year intensive sampling. Science of the Total Environment 466-467, 650-662.

Halden, R.U., 2010. Plastics and Health Risks. Annual Review of Public Health 31, 179-194.

He, W., Qin, N., Kong, X., Liu, W., He, Q., Ouyang, H., Yang, C., Jiang, Y., Wang, Q., Yang, B., Xu, F., 2013. Spatio-temporal distributions and the ecological and health risks of phthalate esters (PAEs) in the surface water of a large, shallow Chinese lake. Science of the Total Environment 461-462, 672680.

Holahan, M.R., Smith, C.A., 2015. Phthalates and neurotoxic effects on hippocampal network plasticity. NeuroToxicology 48, 21-34.

Horn, O., Nalli, S., Cooper, D., Nicell, J., 2004. Plasticizer metabolites in the environment. Water Research 38, 3693-3698.

IARC, 2000. Monograph on the evaluation of carcinogenic risk to humans: some industrial chemicals, di(2-ethylhexyl) phthalate. IARC Monographs 77, 41-148.

Kamrin, M.A., 2009. Phthalate Risks, Phthalate Regulation, and Public Health: A Review. Journal of Toxicology and Environmental Health 12 (2), 157-174.

Latini, G., 2005. Monitoring phthalate exposure in humans. Clinica Chimica Acta 361 (1-2), 20-29.

Li, J., Su, Q., Li, K., Sun, C., Zhang, W., 2013. Rapid analysis of phthalates in beverage and alcoholic samples by multi-walled carbon nanotubes/silica reinforced hollow fibre-solid phase microextraction. Food Chemistry 141 (4), 3714-3720. 
Liou, S., Yang, G.C.C., Wang, C., Chiu, Y., 2014. Monitoring of PAEMs and beta-agonists in urine for a small group of experimental subjects and PAEs and beta-agonists in drinking water consumed by the same subjects. Journal of Hazardous Materials 277, 169-179.

Lyche, J.L., Gutleb, A.C., Bergman, A., Eriksen, G.S., Murk, A.J., Ropstad, E., Saunders, M., Skaare, J.U., 2009. Reproductive and Developmental Toxicity of Phthalates. Journal of Toxicology and Environmental Health 12 (4), 225-249.

Martini, S., Michotey, V., Casalot, L., Bonin, P., Guasco, S., Garel, M., Tamburini, C., 2016. Bacteria as part of bioluminescence emission at the deep ANTARES station (North-Western Mediterranean Sea) during a one-year survey. Deep-Sea Research I 116, 33-40.

Meeker, J.D., Sathyanarayana, S., Swan, S.H., 2009. Phthalates and other additives in plastics: human exposure and associated health outcomes. Philosophical transaction of The Royal Society B 364 (1526), 2097-2113.

Millot, C., 1991. Mesoscale and seasonal variabilities of the circulation in the western Mediterranean. Dynamics of Atmospheres and Oceans 15 (3-5), 179-214.

Munshi, A.B., Karim, N., Shaukat, S., Hashmi, D., Boardman, G.D., Flick, G.J., 2013. Toxicity of Phthalate Esters in Fish and Shellfish from Virginia Beach Using Matrix Solid Phase Dispersion (MSPD) and GC-MS. Journal of The Chemical Society Of Pakistan 35 (6), 1463-1471.

Net, S., Dumoulin, D., El-Osmani, R., Rabodonirina, S., Ouddane, B., 2014. Case study of PAHs, MePAHs, PCBs, Phthalates and Pesticides Contamination in the Somme River water, France. International Journal of Environmental Research 8(4), 1159-1170.

Net, S., Delmont, A., Sempéré, R., Paluselli, A., Ouddane, B. Reliable quantification of phthalates in environmental matrices (air, water, sludge, sediment and soil): A review. 2015 a. The Science of Total Enyironment. 515-516, 162-180. http://dx.doi.org/10.1016/j.scitotenv.2015.02.013.

Net, S., Sempéré, R., Delmont, A., Paluselli, A., Ouddane, B., 2015 b. Occurrence, Fate, Behavior and Ecotoxicological State of Phthalates in Different Environmental Matrices. Environmental Science of Technology 49 (7), 4019-4035. 
Para, J., Coble, P.G., Charrière, B., Tedetti, M., Fontana, C., Sempéré, R., 2010. Fluorescence and absorption properties of chromophoric dissolved organic matter (CDOM) in coastal surface waters of the northwestern Mediterranean Sea, influence of the Rhône River. Biogeosciences 7, 4083-4103.

Pedrotti, M.L., Petit, S., Elineau, A., Bruzaud, S., Crebassa, J.C., Dumontet, B., Marti, E., Gorsky, G., Cozar, A., 2016. Changes in the floating plastic pollution of the Mediterranean Sea in relation to the distance to land. PLoS ONE 11 (8).

Pergent, G., Bazairi, H., Bianchi, C.N., Boudouresque, C.F., Buia, M.C., Clabaut, P., Harmelin, M., Mateo, M.A., Montefalcone, M., Morri, C., Orfanidis, S., Pergent-Martini, C., Semroud, R., Serrano, O., Verlaque, M., 2012. Mediterranean seagrass meadows: resilience and contribution to climate change mitigation. A short summary. IUCN.

Sanchez-Avila, J., Fernandez-Sanjuan,M., Vicente, J., Lacorte, S., 2011. Development of a multiresidue method for the determination of organic micropollutants in water, sediment and mussels using gas chromatography-tandem mass spectrometry. Journal of Chromatography A 1218, 6799-6811.

Sanchez-Avila, J., Tauler, R., Lacorte, S., 2012. Organic micropollutants in coastal waters from NW Mediterranean Sea: Sources distribution and potential risk. Environment International 46, 50-62.

Schmidt, N., Thibault, D., Galgani, F., Paluselli, A., Sempéré, R., 2017. Occurrence of microplastics and potential contribution of phthalates in the surface waters of the Gulf of Lion(NW Mediterranean Sea). Progress in Oceanography, Mermex special issue, submitted.

Sempéré, R., Charrière, B., Van Wambeke, F., Cauwet, G., 2000. Carbon inputs of the Rhône River to the Mediterranean Sea: Biogeochemical implications. Global Biogeochemical Cycles 14 (2), 669-681.

Sempéré, R., Tedetti, M., Panagiotopoulos, C., Charrière, B., Van Wambeke, F., 2008. Distribution and bacterial availability of dissolved neutral sugars in the South East Pacific. Biogeosciences 5, $1165-1173$.

Sempéré, R., Para, J., Tedetti, M., Chattière, B., Mallet, M., 2015. Variability of Solar radiation and CDOM in Surface Coastal Waters of the Northwestern Mediterranean Sea. Photochemistry and Photobiology 91 (4), 851-561.

Serôdio, P., Nogueria, J.M.F., 2006. Considerations on ultra-trace analysis of phthalates in drinking water. Water Research 40 (13), 2572-2582. 
Simoneit, B.R.T., Medeiros, P.M., Didyk, B.M., 2005. Combustion Products of Plastics as Indicators for Refuse Burning in the Atmosphere. Environmental Science of Technology 39 (18), 6961-6970.

Staples, C.A., Peterson, D.R., Parkerton, T.F., Adams, W.J., 1997. The environmental fate of phthalate esters: a literature review. Chemosphere 35 (4), 667-749.

Suaria, G., Avio, C. G., Mineo, A., Lattin, G. L., Magaldi, M.G., Belmonte, G., Moore, C. J., Regoli, F., Aliani, S. 2016. The Mediterranean Plastic Soup: synthetic polymers in Mediterranean surface waters. Nature Scientific Reports 6, 37551 (2016), doi:10.1038/srep37551

The Mermex Group, 2011. Marine ecosystems responses to climatic and anthropogenic forcings in the Mediterranean. Progress in Oceanography 91, 97-166.

Teil, M., Blanchard, M., Dargnat, C., Larcher-Tiphagne, K., Chevreuil, M., 2007. Occurrence of phthalates diesters in river of the Paris district (France). Hydrological Processes 21, 2515-2525.

Tienpont, B., 2004. Determination of Phthalates in Environmental, Food and Biomatrices. An Analytical Challenge. PhD Thesis. Department of Organic Chemistry Ghent University.

Turner, A., Rawling, M.C., 2000. The behaviour of di-(2-ethylhexyl) phthalate in estuaries. Marine Chemistry 68 (3), 203-217.

UNEP Chemicals, 2002. Regionally based assessment of persistent toxic substances. Mediterranean Regional Report, UNEP, Geneve.

Wang, I., Lin, C., Lin, Y., Hsieh, W., Chen, P., 2014. Early life phthalate exposure and atopic disorders in children: A prospective birth cohort study. Environment International 62, 48-54.

Wang, F., Xia, X., Sha, Y., 2008. Distribution of Phthalic Acid Esters in Wuhan section of the Yangtze River, China. Journal of Hazardous Materials 154, 317-324.

Wofford, H.W., Wilsey, C.D., Neff, G.S., Giam, C.S., Neff, J.M., 1981. Bioaccumulation and metabolism of phthalate esters by oysters, brown shrimp, and sheepshead minnows. Ecotoxicology and Environmental Safety 5 (2), 202-210. 
Xie, Z., Ebinghaus, R., Temme, C., Caba, A., Ruck, W., 2005. Atmospheric concentrations and airsea exchanges of phthalates in the North Sea (German Bight). Atmospheric Environment 39, 3209 3219.

Xie, Z., Selzer, J., Ebinghaus, R., Caba, A., Ruck, W., 2006. Development and validation of a method for the determination of trace alkylphenols and phthalates in the atmosphere. Analytica Chimica Acta 565, 198-207.

Xie, Z., Ebinghaus, R., Temme, C., Lohmann, R., Caba, A., Ruck, W., 2007. Occurrence and Air-Sea Exchange of Phthalates in the Arctic. Environmental Science of Technology 41, 4555-4560.

Xu, B., Gao, N., Sun, X., Xia, S., Rui, M., Simonnot, M., Causserand, C., Zhao, J., 2007. Photochemical degradation of diethyl phthalate with UV/H2O2. Journal of Hazardous Materials 139 (1), 132-139.

Yang, G.C.C., Yen, C., Wang, C.,, 2014. Monitoring and removal of residual phthalate esters and pharmaceuticals in the drinking water of Kaohsiung City, Taiwan. Journal of Hazardous Materials, $27753-61$.

Yoro, S.C., Panagiotopoulos C., Sempere, R., 1999. Dissolved organic carbon contamination induced by filters and storage bottles. Water Research 33 (8), 1956-1959.

Zeng, F., Cui, K., Xie, Z., Liu, M., Li, Y., Lin, Y., Zeng, Z., Li, F.,, 2008. Occurrence of phthalate esters in water and sediment of urban lakes in a subtropical city, Guangzhou, South China. Environment International 34, 372-380.

Zhang, X., Zhang, L., Li, L., Feng, Y., Chen, B., Ma, J., Huynh, E., Shi, Q., De Felici, M., Shen, W., 2013. Diethylhexyl phthalate exposure impairs follicular development and affects oocyte maturation in the mouse. Environmental and Molecular Mutagenesis 54 (5), 354-361.

Zorita, I., Apraiz, I., Ortiz-Zarragoitia, M., Orbea, A., Cancio, I., Soto, M., Marigomez, I., Cajaraville, M.P., 2007. Assessment of biological effects of environmental pollution along the NW Mediterranean Sea using mussels as sentinel organisms. Environmental Pollution 148 (1), 236-250. 